\title{
Contacto y pérdida: el español y las lenguas indígenas en el Río de la Plata entre los siglos XVI y XIX
}

\author{
Virginia Bertolotti y Magdalena Coll ${ }^{*}$ \\ Universidad de la República, Uruguay
}

\begin{abstract}
Resumen
Este trabajo analiza el contacto lingüístico histórico entre las lenguas indígenas y el español en el actual territorio uruguayo y las razones de su resultado, a saber, el desplazamiento y pérdida de lenguas indígenas autóctonas en el Río de la Plata. Propone dos etapas en la historia lingüística del contacto entre españoles e indígenas de diversas etnias. Una de acercamientos iniciales (siglo XVI) y otra que se corresponde con el establecimiento y colonización europeos (siglos XVII y XVIII) y que culmina con la aculturación lingüística de los indígenas (siglo XIX). Se identifican cuatro tipos de circunstancias que explican la pérdida de las lenguas indígenas: las circunstancias sociodemográficas, las circunstancias etnolingüísticas, las circunstancias histórico-culturales y las circunstancias tecnológicas. La identificación de estas últimas es el aporte más original al considerar la apropiación de la escritura como una razón para el desplazamiento hacia el español.
\end{abstract}

\footnotetext{
Para correspondencia, dirigirse a: Virginia Bertolotti (virginia.bertolotti@gmail. com) o Magdalena Coll (collmagdalena@gmail.com), Instituto de Lingüística, Facultad de Humanidades y Ciencias de la Educación, Universidad de la República, Magallanes 1577, Montevideo, Uruguay.
} 
Palabras clave: contacto lingüístico español-lenguas indígenas, desplazamiento y pérdida, Río de la Plata.

\title{
Contact and loss: Spanish and Indigenous languages IN the Río de la Plata Between the $16^{\mathrm{TH}}$ AND THE $19^{\mathrm{TH}}$ CENTURY
}

\begin{abstract}
This paper analyzes the historical linguistic contact between indigenous languages and Spanish in the current territory of Uruguay as well as the reasons for its outcome, namely the displacement and loss of autochthonous languages in the Río de la Plata. The study proposes two stages to describe the history of language contact between the Spaniards and the indigenous peoples: while the first one ( $16^{\text {th }}$ century) is characterized by the initial encounters between both, the second one $\left(17^{\text {th }}\right.$ and $18^{\text {th }}$ century) is characterized by European settlement and colonization, which led to the linguistic acculturation of the Indigenous peoples in the 19th century. The loss of indigenous languages is explained by four types of circumstances: sociodemographic, ethnolinguistic, cultural-historical, and technological circumstances. In particular, the characterization of the latter provides an original insight into the appropriation of writing as one of the factors which favored the shift from indigenous languages to Spanish.
\end{abstract}

Key words: language contact, Spanish-indigenous languages, shift and loss, Río de la Plata.

Recibido: $31 / 08 / 13$

Aceptado: 16/10/13

\section{INTRODUCCIÓN}

Desde hace algunas décadas, diferentes grupos de estudiosos han venido trabajando en la reconstrucción sistemática de la historia lingüística rioplatense. En el caso de Uruguay, se han realizado estudios históricos sobre el español, sobre el portugués en contacto con el español y sobre lenguas africanas en contacto con el español ${ }^{1}$. Sin embargo, no se han realizado

1 La producción existente de estudios histórico-lingüísticos sobre el español se sintetiza en Bertolotti y Coll (2006 y 2010); la existente sobre los estudios del histórico entre el español 
estudios sobre el contacto con lenguas indígenas, ni sobre el desplazamiento y pérdida de (algunas de) ellas. Una mirada histórico-lingüística sobre el contacto de estas lenguas con el español y las circunstancias que llevaron a su posterior desaparición en el territorio del actual Uruguay es el objeto de este trabajo ${ }^{2}$.

Si bien la temática de las lenguas indígenas del Río de la Plata no es novedosa en el ámbito de los estudios filológicos, estos, realizados mayoritariamente en la primera mitad del siglo Xx, se han centrado en otras cuestiones propias de los énfasis disciplinarios de la época. El erudito estudio de da Rosa (en proceso) recoge todos los antecedentes de trabajos realizados en ese período sobre las lenguas indígenas habladas en el contexto rioplatense. Pone en evidencia que el conocimiento específico sobre las modalidades lingüísticas en cuestión no podrá avanzar más allá de la postulación de la existencia de algunos ítems léxicos y de la especulación sobre algunas cuestiones filogenéticas, en la medida en que no aparezcan nuevos datos, lo cual parece, en principio, poco probable. Asimismo, el estado del arte presentado por da Rosa nos permite afirmar que no ha existido una reflexión sobre el contacto de las lenguas indígenas con el español ni sobre el proceso de sustitución de las primeras por el último.

Es por ello que en este artículo nos ocupamos de documentar el proceso en el que las poblaciones indígenas rioplatenses dejaron de usar algunas de sus lenguas originarias e incorporaron el español como su instrumento de comunicación principal y cotidiano.

Las fuentes para analizar las modalidades lingüísticas que coexistieron con el español son, básicamente, de tres tipos. Las primeras son documentos históricos de archivo, como, por ejemplo, causas judiciales, informes a autoridades civiles o religiosas. Las segundas fuentes son documentos de época producidos con el fin del registro lingüístico. Tal es el caso del Compendio del idioma de la Nación Chaná, del sacerdote Dámaso Antonio Larrañaga (1923 [1815]), del Códice Vilardebó (ápud Gómez Haedo 1937) o del Catecismo de guenoa incluido en el Saggio prattico delle lingue del abate Hervás y Panduro (1787). Estos registros constituyen los únicos documentos en los que se asocia el nombre de una lengua indígena de la región con un

y el portugués en territorio uruguayo, en Coll (2008) y la existente sobre los estudios acerca de las lenguas africanas, en Coll (2010).

2 Este artículo se inscribe en la investigación financiada por la Comisión Sectorial de Investigación Científica de la Universidad de la República (llamado I+D, 2010). Fue realizada en el marco de los trabajos del Grupo de investigación de CSIC 1148, "Estudios lingüísticohistóricos del Uruguay". 
conjunto de voces o expresiones. Sin embargo, se trata de obras que no llegan a constituirse en gramáticas o vocabularios propiamente dichos, lo que marca una diferencia sustancial entre los recursos para el estudio de estas lenguas y los recursos (gramáticas, artes, lexicones y vocabularios) para el estudio de otras lenguas, provenientes de otras regiones americanas. Las terceras fuentes son testimonios de viajeros y cronistas de época. Estos se caracterizan, en cuanto a la temática indígena, por asociar lenguas a etnias (o naciones, al decir de la época) y aportan fragmentariamente información léxica sobre lenguas indígenas hoy extintas. Ejemplo de este tipo de fuentes son algunas de las publicaciones de Félix de Azara o de D'Orbigny, analizados por Bértola (2013), entre otras.

En este trabajo, presentamos fundamentalmente el análisis lingüístico del primer tipo de fuentes: documentos de archivo de interés histórico y antropológico, sobre todo, aquellos de publicación reciente ${ }^{3}$.

En el apartado 1, presentamos información sobre las modalidades lingüísticas y las características antropológicas de las poblaciones preexistentes a la llegada europea al Río de la Plata, con énfasis en el actual territorio uruguayo. Asimismo, proponemos dos etapas en la historia lingüística del contacto. En el apartado 2, postulamos las circunstancias que habrían favorecido la sustitución de las lenguas indígenas hoy extintas. Cierra este artículo el apartado 3 en el que realizamos algunas ponderaciones finales.

3 Tal es el caso, por ejemplo, de un documento sobre la insurrección indígena en Santo Domingo de Soriano en 1686. Se trata de un texto de 105 folios, ubicado en el Archivo General de Indias (Sección Gobierno, Subsección Charcas, Legajo N 283) y transcripto por Rogelio Brito, y adecuado y publicado recientemente con un estudio introductorio y notas, por Bracco y López Mazz (2006). El análisis lingüístico de este expediente realizado en Bertolotti (2011a) aporta datos sobre las variedades lingüísticas presentes en la reducción y sus ámbitos de uso hasta ahora no destacados. Allí se concluye que parecería haber dos lenguas vehiculares en la época (1686): el español y el guaraní. Asimismo, entiende, entre otras cosas, que no había intercomprensibilidad entre guaraní y "charrúa" ni entre guaraní y "serrano". La no intercomprensibilidad entre las lenguas existentes podría haber favorecido la posterior adopción del español. Encontramos en este tipo de documentos colectados con fines históricos, esporádicas transcripciones de fragmentos en lengua indígena, que podrían ser considerados fuentes para su conocimiento, de lo cual no nos ocuparemos en esta ocasión. 


\section{LAS MODALIDADES LINGÜÍSTICAS, SUS HABLANTES Y LAS ETAPAS DEL CONTACTO LINGÜÍSTICO ENTRE INDÍGENAS Y EUROPEOS}

Los pobladores originarios del espacio territorial y cultural que hoy denominamos rioplatense ${ }^{4}$ estarían establecidos en la zona desde hace unos 10500 años. Como ya se ha sintetizado en Bertolotti (2011b), al momento de la llegada de los europeos, este territorio del Uruguay estaba ocupado por grupos indígenas ágrafos que sin desconocer la práctica de la agricultura, dependían esencialmente de la pesca, de la recolección y de la caza para su subsistencia. Con estos recursos como base económica, el desarrollo demográfico era escaso y puede estimarse en unos pocos miles de personas. Estas habrían constituido grupos dispersos pero no aislados entre sí, que se contactaban para satisfacer sus necesidades de intercambio en función de periódicas u ocasionales concentraciones de recursos.

Es relevante señalar que no hay acuerdo sobre qué etnias poblaban este territorio, ni cuántas personas conformaban cada una de ellas ni cuáles eran sus actividades de subsistencia predominantes.

Según Vidart (2000: 10), en el siglo XVI la población de la zona se dividía entre los pertenecientes a una macroetnia charrúa con características más afines a los grupos de la Pampa y de la Patagonia y los pertenecientes a grupos más afines a aquellos existentes en Brasil.

Este mismo autor muestra cómo este panorama cambia en el siglo XVIII con el establecimiento de unos 30000 guaraníes en las misiones jesuíticas y su posterior dispersión por este y otros territorios del sur del Brasil. Por su parte, Bracco (2004) es más enfático en cuanto a la presencia dominante guaraní en el momento de la llegada de los europeos, así como en cuanto a la densidad poblacional. Basado en estudios arqueológicos sobre los cerritos de indios, este autor sostiene que el cálculo más conservador sobre las fuerzas humanas necesarias para su construcción hace pensar en una población mayor a las concentraciones propias de bandas de cazadores. Más recientemente, Bracco y López (2010) se afilian a la tesis de una población de base guenoa-minuán, sin descartar de plano que se tratara de un grupo culturalmente guaraní con algunas peculiaridades que hacían de ellos una nación. En Rona (1964), una de las pocas obras que se ocupa del tema

\footnotetext{
4 La zona de la cuenca del Río de la Plata se identifica socioculturalmente a partir de los núcleos poblacionales de Buenos Aires, Montevideo, Rosario, La Plata y sus zonas de influencia más inmediata.
} 
indígena con una perspectiva lingüística científica, se señala la existencia de un "gran complejo charrúa".

Las manifestaciones materiales conservadas de estos cazadores, recolectores y agricultores primitivos se limitan a diversos tipos de productos líticos (boleadoras, morteros, puntas de flecha, rompecabezas, entre otros), a productos en hueso, en madera y en cerámica de factura elemental (Consens 1997). De acuerdo con los estudios arqueológicos más recientes, todo el litoral platense presenta las mismas características en cuanto al acervo material dejado por sus habitantes -características que presentan rasgos similares a lo largo de los últimos 5000 años-. Su sello identitario más claro es un estilo de "ribereños plásticos" y, junto a este, aunque en una escala cuantitativamente menor, se encuentra otro estilo denominado -también arqueológicamente- como "guaraní", según Farías y Lezama (en prensa). También de acuerdo con estos autores, en el hoy territorio uruguayo, los testimonios que más nos acercan a la descripción de quienes eran los pobladores indígenas del litoral al momento de la llegada de los europeos son los que resultan de la expedición de Sebastián Gaboto que circuló por la zona entre 1527 y 1530 . De estos surgen las denominaciones de agrupamientos indígenas: los "beguá-charrúas", los "beguá-chaná" y los "guarenis-chandrischandules", a los cuales otros cronistas agregan "Charruases, Guaraníes, Chanaes, Chanaes Atembures, Carcaraes, Carandíes y Atambúes" (Farías y Lezama, en prensa).

En síntesis, no parece haber certezas sobre los agrupamientos humanos y sus identidades culturales que nos permitan trazar fronteras claras y, como veremos, tampoco son claras las posibles asociaciones entre grupos humanos y modalidades lingüísticas.

No obstante ello, el análisis de la comunicación lingüística entre indígenas y europeos y el de las lenguas usadas por unos y otros nos han permitido identificar y periodizar dos etapas lingüísticamente relevantes: la de los primeros contactos (siglo XVI) y la del establecimiento y colonización europeos (siglos XVII y XVIII), que culminará con la aculturación lingüística de los indígenas (siglo XIX).

Para la mejor comprensión de las etapas que proponemos, presentamos muy sintéticamente el proceso poblacional de este territorio.

Dos de los primeros grupos europeos llegados al hoy territorio uruguayo fueron aquellos comandados por Juan Díaz de Solís en 1516, quien muere a manos de los indígenas, y aquellos quienes venían con el piloto mayor Sebastián Gaboto en 1527. Tendrá que pasar un siglo para que haya un 
establecimiento europeo en el actual territorio uruguayo. En $1624^{5}$, los misioneros franciscanos instalan la reducción de Santo Domingo de Soriano en el Río Negro. El siguiente establecimiento europeo en territorio uruguayo actual se da medio siglo después. Se trató de un grupo de origen portugués que funda Colonia del Sacramento, frente a Buenos Aires, en 1680. Pasará casi otro medio siglo para que la Corona española se establezca formalmente al fundar San Felipe y Santiago de Montevideo entre 1724 y 1726.

Los PRIMEROS CONTACTOS ¿Qué sucedió, desde el punto de vista lingüístico, cuando las culturas indígenas y la hispana se ponen en contacto? Aparecen los primeros intérpretes naturales, eso es, aquellos que "desempeña[n] espontáneamente funciones de intermediación lingüística" (Alonso Araguás 2010: 55), entre lenguas indígenas y europeas.

Podemos documentar las dos caras de esos primeros acercamientos. Una muestra europeos que aprenden lenguas indígenas y luego se convierten en mediadores entre los suyos y los indígenas y la otra cara muestra indígenas que aprenden español y que también median entre nativos y conquistadores.

Los europeos que aprenden lenguas indígenas en el Río de la Plata son náufragos. Bien conocido es el caso de Francisco del Puerto, sobreviviente de la expedición de Juan Díaz de Solís (1516), que en 1528 es encontrado por Sebastián Gaboto. Del Puerto, durante la convivencia con sus captores, había aprendido la lengua indígena, lo que le permitió mediar entre europeos y nativos (Medina 1908, ápud Lezama 2008: 15).

La contracara de esta situación lingüística son los indios que tempranamente hablan español, como los llevados por Gaboto a España (Medina 1908, ápud Lezama 2008: 28), es decir, los primeros indígenas capturados y que podrían oficiar de "lenguas". Veamos un fragmento de una Real Cédula ${ }^{6}$, transcripto directamente de Medina,

Nuestros oficiales que residis en la cibdad de Sevilla, en la Casa de la Contratación de las Indias. Yo he sido informado que el capitán Sebastián Caboto al tiempo que se venía para estas partes del viaje que hizo, estaban en la isla de Santa Catalina ciertos indios que se habían tornado cristianos, entre los cuales estaban un indio é una india, que el indio se

\footnotetext{
5 La fecha concreta de la fundación de Santo Domingo es un tema polémico entre los historiadores (cfr. Barrios Pintos 1971: 251).

6 Real Cédula á los Oficiales de la casa de la Contratación para que averigüen é den informe de un indio é india que trajo Sebastián Caboto (...). Archivo de Indias, estante 148, cajón 2, legajo 2, libro II, fol.1 (Medina 1908: 101).
} 
llamaba Pedro é la india María, los cuales le rogaron que los trajese a tierra de cristianos en su compañía, pues eran cristianos, é que así los trajo a esa ciudad, é que las personas que los tienen en su poder los tratan é los tienen como esclavos, é que la dicha María la han querido vender, é porque diz que son hijos de personas principales é saben muy bien nuestra lengua é podrían aprovecharse si Nos enviásemos alguna $\operatorname{armada}^{7}$ (Medina 1908: 101-102).

Esto fue una práctica extendida y se ha sostenido que "al parecer en 1570 ya existían más de cien intérpretes solo en la ciudad de Quito (Ecuador)" (Merma Molina 2005: 173).

EL ESTABLECIMIENTO Y LA COLONIZACIÓN EUROPEOS. Durante este período (siglos XVII y XVIII), y como en la etapa anterior, podemos constatar dos situaciones paralelas: hubo tanto hablantes de lenguas indígenas que aprendieron español, como hablantes de español que aprendieron lenguas indígenas.

Entendemos que los primeros lo hacen en el marco mayor de un proceso de aculturación en el que incorporarse a la nueva cultura era, en última instancia, una estrategia de supervivencia. Los segundos, de quienes no nos ocuparemos en este trabajo, encuentran en el aprendizaje de las lenguas indígenas algún tipo de ventaja -la conquista de las almas, mejor posición para el comercio- que no supone, sin embargo, una filiación cultural permanente.

En otras palabras, la mayoría de los españoles no aprendían lenguas indígenas, no asumían esa parte de las culturas indígenas, en tanto que los indígenas que se hispanizan van a aprender el español como parte de un proceso mayor que se evidencia también en la incorporación del hierro, de la vestimenta europea, de algunos ritos religiosos e incluso del cambio de nombre propio, forzado o no. Los distintos protagonistas aprenden la lengua del otro desde lugares distintos: a los unos les fue cambiada la realidad y se ven inmersos en un proceso de adaptación a las nuevas circunstancias determinadas por la presencia europea; los otros quieren cambiar la sociedad y adecuar la ya existente a sus necesidades vitales, religiosas, económicas.

Si bien no podemos datar con precisión el proceso de sustitución de algunas lenguas indígenas por el español, desde comienzos del siglo XIX se pueden encontrar síntomas de la conciencia de que muchas de las lenguas indígenas se están perdiendo. Un observador lúcido de esta realidad fue

\footnotetext{
Estos y todos los siguientes resaltados son nuestros.
} 
Larrañaga, quien en ocasión de la inauguración de la primera biblioteca pública en Uruguay, el 26 de mayo de 1816, señalaba lo siguiente con respecto a las lenguas indígenas:

Nuestra provincia presenta una cosa muy singular ( ) este pequeño recinto cuenta con más de seis idiomas diferentes: tales son el minúan, el charrúa, el boane, el goanoa, el guaraní y qué se yo más? Pero lo más sensible de todo es, que en poco tiempo no quedará vestigio alguno de ellos; y así es honor nuestro el conservarlos (Larrañaga 1951 [1816]: 33).

Por otra parte, en esa misma década, Larrañaga consultó a unos hablantes, que a su juicio, estarían entre los últimos de la lengua chaná y, a partir de ese ejercicio, confeccionó el Compendio del idioma de la Nación Chaná, ya mencionado.

En las décadas del 30 y del 40 del siglo XIX, y con una preocupación similar, el doctor Teodoro Vilardebó requerirá información a supuestos hablantes de charrúa para realizar sus dos trabajos de registro de voces de diversos campos semánticos, entre los cuales el de la numeración, que publicará, casi un siglo después, como ya hemos mencionado, Gómez Haedo (1937).

Estos esfuerzos de compilación son testimonio de que en menos de una decena de generaciones después de la llegada de los españoles las lenguas habladas por las poblaciones originarias estaban en claro proceso de desaparición.

A continuación proponemos las circunstancias que, a nuestro juicio, habrían favorecido esta desaparición y la consecuente sustitución de las lenguas indígenas por el español.

\section{CIRCUNSTANCIAS QUE HABRÍAN FAVORECIDO LA SUSTITUCIÓN DE LAS LENGUAS INDÍGENAS POR EL ESPAÑOL}

Las circunstancias que trataremos aquí, alguna de las cuales se solapan, incluyen (2.1) las sociodemográficas, (2.2) las etnolingüísticas, (2.3) las histórico-culturales y (2.4) las que denominamos tecnológicas. 


\subsection{Circunstancias Sociodemográficas}

Además de la pérdida de vidas por la presencia de enfermedades nuevas para la población autóctona como señala profusamente Consens (2010) y documenta para el Río de la Plata Pi Hugarte (2005), la extinción física se dio por el trabajo forzado y por las guerras, cuya expresión más dramática es la matanza de los charrúas en Salsipuedes en 1831. Por otra parte, la disminución étnico-demográfica se da también por la unión -voluntaria o no- entre mujeres indígenas y hombres españoles, por la incorporación de indígenas a la sociedad hispana a través del procedimiento del "rescate" o por el procedimiento de "reparto de la chusma".

Estas circunstancias demográficas explican la extinción de algunas de las etnias cuyas modalidades lingüísticas se hablaron en este territorio. Huelga decir que no todas se extinguieron. El guaraní se habla en nuestros días en otros lugares de América y, de hecho, se siguió hablando en territorio uruguayo hasta entrado el siglo XIX "en las últimas clases de la gente de nuestra campaña," como testimonia Andrés Lamas en su discurso inaugural del Instituto Histórico Geográfico Nacional en el año 1843 (Lamas y Blanco Acevedo 1922: 70)9 . El destino final del guaraní será otro por ser también la lengua de la conquista, no quizás la de la Corona española, pero sí la de la evangelización, por ejemplo, en las misiones jesuíticas. El trabajo de estos religiosos, además de la construcción de ciudades y de la explotación de ingenios, también consistió en la gramatización de la lengua guaraní, como es bien sabido.

\subsection{CirCunSTANCIAS ETNOLINGÜÍSTICAS: LA DIVERSIDAD LINGÜÍSTICA COMO PARTE DE LA CULTURA PREEUROPEA}

Ha sido profusamente señalada la variedad de lenguas indígenas preexistentes a la llegada europea (Martinell1992). En esta región, testimonios como el de Félix de Azara, entre otros, dan cuenta de ello todavía a fines del siglo

\footnotetext{
8 Se entendió por "rescate" el mecanismo por el cual se recuperaba a un integrante de una etnia que había caído prisionero de otra. Se llamó "reparto de la chusma" al procedimiento de distribución de los indígenas sin capacidad bélica, esto es, mujeres, niños y ancianos, entre los españoles.

9 Esto también se refleja en la literatura. Por ejemplo, en la novela histórica Nativa (1889), su autor Eduardo Acevedo Díaz representa a los personajes indígenas, que participaron en las guerras independentistas, hablando guaraní.
} 
XVIII y principios del XIX. El naturalista español distingue seis naciones indígenas para la zona rioplatense: la nación charrúa, los indios yaros, los indios bohanes, los indios chanás, los indios minuanes y los indios guaraníes, y afirma que cada nación tiene su idioma propio (Azara 1847: 143). Tiempo después, D'Orbigny (1839) sostiene que la nación charrúa estaba integrada por chanás, bohanes, yaros y minuanes y que sus miembros hablaban dialectos que provenían de la lengua de la nación charrúa, que, a su vez, formaba parte de la rama y raza pampeanas (ápud Bértola 2013: 29). Nótese que aunque estos testimonios pertenecen al siglo XIX recogen ciertamente una diversidad lingüística preexistente a la llegada de los españoles, y que no es ajena a los procesos que estudiamos.

En el marco de esta diversidad lingüística, la figura de los mediadores habría estado naturalizada. Martinell (1992: 153), quien trabaja sobre todo con los virreinatos primeros (Nueva España y el Perú), señala que preexistía a la conquista la práctica de la mediación y que, por tanto, la adquisición o el aprendizaje de la lengua "del otro" no era ajena a las culturas precolombinas.

En el Río de la Plata, podemos documentar la existencia de hablantes nativos de una lengua indígena adquirida o aprendida. Veamos, como ejemplo, el caso de Lucía, una mujer de origen guenoa-minúan en poder de un cacique charrúa, hablante de la lengua de su captor, como atestigua un documento de 1665 (López Mazz y Bracco 2010: 17-18).

Asimismo, en Levinton ( $\mathrm{s} / \mathrm{d}$ ) hay testimonios de caciques charrúas que se expresaban en contextos interétnicos en una lengua denominada como guaraní, así como en Bracco y López Mazz (2010: 42 y 44) hay testimonios de guenoas-minuanes que hablaban guaraní e incluso uno que habla "castellano con bastante propiedad, perfectamente guaraní, charrúa y minuán" (López Mazz y Bracco 2010: 237).

Interpretamos que la incorporación de una nueva lengua al repertorio comunicativo de los indígenas de la zona era una práctica naturalizada y, por tanto, no ajena a la historia cultural de esos pueblos.

Por otra parte, la adopción de una lengua como vehículo de comunicación entre diversos grupos era también una práctica instalada (Martinell1992: 172). Tal parece haber sido el caso del guaraní, cuya denominación como "lengua general" es frecuente en la documentación. Que el español, nueva lengua, se convirtiera en una lengua vehicular sería un cambio menor en una práctica cultural ya instalada. 


\subsection{Circunstancias históRICO-CUlturales}

La colonización trae como consecuencia la imposición de muchos aspectos de la cultura material e inmaterial hispana, a través de procedimientos, más o menos planificados, por los cuales la cultura hispana, y con ella la lengua española, terminan por prevalecer en la región.

Como ya señalamos en el apartado El establecimiento y la colonización europeos, se da un proceso cuyo primer paso necesario pero no suficiente es la presencia de indígenas hablantes de español. Además de los casos ya referidos en dicho apartado, es posible documentar la existencia de otros procedimientos, más tardíos, para obtener intérpretes indígenas, es decir, un reducto de bilingües dentro de la comunidad lingüística indígena, como ilustra el siguiente testimonio de maestre de campo Francisco Domínguez, del año 1689:

algunos de los dichos rescatados se fueron a sus tierras con permiso que se les dio de parte de los españoles, y por medio de ellos casi se llegaron a reducir los de su nación, como así sucedió con un indio llamado Matheo, que fue rescatado por Diego Martínez, el cual fue instrumento para que ese redujese treinta familias a la doctrina del Yapeyú, una de las que tienen a su cargo los dichos religiosos de la Compañía de Jesús, y así, por este medio se conseguía que haciéndose ladinos los dichos rescatados, servían de intérpretes y lengua para tratar con los demás de tierra adentro, de que se seguían varias utilidades del servicio de ambas majestades (López Mazz y Bracco 2010: 65-66).

En este fragmento se da cuenta del procedimiento de aprendizaje del español como consecuencia del rescate. Este procedimiento, similar al robo de mujeres, permitía tender lazos de comunicación entre el mundo europeo y el mundo indígena. Un medio aún más violento de incorporación de hablantes de lenguas indígenas a la sociedad colonial fue el reparto de la chusma, como ya mencionamos.

La incorporación a la sociedad europea se habría dado también en circunstancias no necesariamente violentas. En el marco de un acuerdo con los minuanes, en el año 1762, se le ofrece a su cacique Cumandat el cuidado de su progenie:

Se les expuso que viesen si buenamente y no de otro modo querían, por su sola libre voluntad, abrazar nuestra santa fe, como igualmente si trayendo sus familias a esta jurisdicción quisiesen dar y poner sus hijas e hijos en casas particulares donde fuesen su voluntad, así en casa del señor gobernador, en la del maestre de campo y otras semejantes, 
para que fusen atendidas en vestirlas, cuidarlas y atenderlas en todo, desde luego serían recibidas con el mayor amor y cariños, y todos bajo la voluntad de ellos, pues en manera alguna se pretendía usurparles el domino y mando que tenían como padres de ellas (...) (López Mazz y Bracco 2010: 197).

La expresión lingüística de esta inmersión forzada en la sociedad colonial es la incorporación del español que supondrá a corto y mediano plazo el desplazamiento y la pérdida de las lenguas indígenas.

El aprendizaje del guaraní fue también un factor de desplazamiento de otras lenguas indígenas. Para esta época, hablar guaraní no solo se explica por su condición de lengua vehicular, sino también por una circunstancia socio-cultural europea, que es la difusión de la religión católica, que se hizo, en este territorio, principalmente en guaraní.

Tanto el aprendizaje del español como el aprendizaje del guaraní redundan a largo plazo en la extinción de las otras lenguas autóctonas ${ }^{10}$. Por citar uno entre muchos ejemplos, reproducimos un fragmento del relato del padre Lozano, sobre Miguel Ximénez, cura de San Borja, donde encontramos a guenoa-minuanes en la situación de aprender guaraní:

No obstante, a 24 de enero de 1731 se lograron tres almas de esta nación que fueron marido y mujer, y un hijo de pecho, que fue bautizado, y sus padres quedaban instruyéndose en la lengua guaraní para ser catequizados (Bracco y López Mazz 2010: 131).

No solo vehiculizaba el guaraní contenidos religiosos sino también de índole política, como podemos ver en el acuerdo con los minuanes de 1762. De allí extraemos otros fragmentos en los que leemos que Manuel Domínguez, maestre de campo, habla guaraní y es esa lengua la que le permite la comunicación con el cacique minúan que también la entiende:

Y para el mejor acierto de este particular se dispuso se hallasen presentes en esta sala (como lo estuvieron) el maestre de campo de milicias don Manuel Domínguez, y el capitán de vecinos don Juan Antonio Artigas, con quienes conferenciándose el asunto se hizo al mismo tiempo venir a esta sala a los referidos indios, a quienes mandándoles tomar asiento, por el referido maestre de campo, como hábil en la lengua guaraní, por entender también muy bien ésta el referido cacique, se le ordenó

\footnotetext{
10 Algunos comentarios sobre el rol de la lengua guaraní en territorio hoy uruguayo pueden encontrarse en Curbelo y Bracco (2004).
} 
de parte del señor gobernador y asimismo por este ayuntamiento, se le hiciesen (como se le hicieron) al dicho indio cacique la preguntas y exposiciones siguientes: preguntado cual era el cacique principal de los indios que estaban en estas inmediaciones respondieron los presentes que todos conocían por cacique de ellos al referido indio Cumandat (López Mazz y Bracco 2010: 195).

El guaraní se presenta también como lengua que permite la comunicación en contextos de administración de justicia. En Bertolotti, Coll y Polakof(2010: 254) se incluye un documento en el que Antonio Villanueva, lenguaraz del guaraní al español, traduce los testimonios de tres indígenas acusados de haber robado caballos en el campo del Real de San Carlos. Declara que "posee la lengua guaraní como la castellana que está hablando". También Bértola y Fernández (2011) aportan ejemplos tomados de documentos históricos en los que se pone de manifiesto que el guaraní es lengua de comunicación.

\subsection{Circunstancias tecnológicas}

Desde los trabajos de Ong (1985), parece haber acuerdo entre los lingüistas en considerar la lengua escrita como una tecnología que desempeña un papel social de extrema relevancia. En tal sentido, interpretamos que tiene que ser vista como un factor fundamental en el análisis del desplazamiento de las lenguas indígenas autóctonas ${ }^{11}$. La lengua escrita suponía el acceso al mundo de los privilegios europeos y hacía la diferencia entre la vida y la muerte o, menos dramáticamente, aseguraba la libertad de circulación o la propiedad, a través del uso de títulos, licencias selladas, pasaportes, certificados, cartas, entre otros. Mostramos a continuación algunos ejemplos.

En el contexto de una disputa por tierras de los pueblos de las Misiones de San Borja y Apóstoles, el padre Miguel Ximénez relató lo que le contó en su lecho de muerte un guenoa de 60 años:

Este indio[Joseph Gueyancaí] pues siendo alcalde ordinario en este años de 1728 me llamó en el artículo de su muerte el día que recibió el viático y extremaunción y díchole por mi compañero la recomendación de su alma; fui, y al entrar me dijo que me diera prisa porque ya le quería

11 En Bertolotti (2011b: 113, nota 83) se había señalado esto mismo como una hipótesis a explorar. 
llevar el Señor. Preguntele lo que quería y me dijo estas palabras: padre, he tenido noticia, como vos también sabéis como muchas veces te dije que los [indígenas] de los Apóstoles se apropiaban la estancia de Ybirapatá que les había prestado por breve tiempo, y que ellos (id est los apostolinos) habían hecho títulos de propiedad y donación sin avisarnos, y hécholos firmar a los padres provinciales (...) (López Mazz y Bracco 2010: 118-9).

En 1732, Zabala, Gobernador de Buenos Aires, describe el hecho de que los caciques deberían respetar la vida de los españoles que tuvieran "licencia de este gobierno sellada":

Establecerán con dichos caciques que a ningún español, que fuere con licencia de este gobierno sellada por armas se haga daño alguno, pero a los que no la llevaron no se les permita hacer faena alguna, y mucho menos a los changadores por ser estos los que hurtan los caballo y cometen las maldades (López Mazz y Bracco 2010: 133).

En el mismo sentido, se les otorga a los indígenas pasaporte en el año 1762, en el marco de otro tratado entre los minuanes y el Cabildo de Montevideo. Nótese además que se les había avisado a los indígenas que el tratado quedaba por escrito para que "fuese inviolable" por ambas partes, lo que implicaba la presuposición de un conocimiento por parte de los involucrados del valor social de la lengua escrita:

Fueron prevenidos de que todo lo que habían tratado quedaba aquí por escrito y sentado para que fuese inviolable en todo tiempo su complimiento por ambas partes, así por parte de este gobierno y ciudad, como parte de ellos, y que también se les daría el correspondiente pasaporte para que asegurase su ida y salida de esta jurisdicción en demanda del paradero de su gente (López Mazz y Bracco 2010: 198200).

Este hecho se comprobará, más adelante en el relato histórico del tratado:

[e]n comprobación delo cual ha conducido el dicho cacique Cumandat un pasaporte que le dio en Misiones el capitán don Antonio Catani, quien expresa en él haberle asegurado el dicho Cumandat se conducía a esta ciudad a cumplir la palabra que aquí había dado de su retorno, asegurando el dicho Cumandat (...) (López Mazz y Bracco 2010: 198-200).

Un año después de la firma del tratado, se lo revisa y se entera a los indígenas que se publicará un bando como una forma de poner en conocimiento de toda la población el estatus obtenido por los minuanes en el tratado: 
Y así mismo se les hizo enterar por medio de la dicha india lenguaraz o intérprete de dichos indios, y ladina en nuestro idioma, que para asegurarles nuestra amistad, además de las razones dichas, haría publicar bando el señor gobernador para que no fuesen hostilizados ni molestados por nadie de aquí de la ciudad, ni aun de los nuestros de la campaña, para lo cual llevarían papel de seguro, a mayor abundamiento, de mano de su señoría, como también viesen (...) (López Mazz y Bracco 2010: 202).

El reconocimiento del valor práctico de los elementos escritos también fue testimoniado por Don Pernetty en "Noticias sobre los minuanes", de 1763. Relata cómo los indígenas conocían el valor político y civil de un texto escrito más allá de que, como señala el propio Pernetty, desconocieran la lengua en que estuviera escrito:

Al encontrar las puertas cerradas, los indios se aproximaron a la ventana donde nosotros estábamos, y uno de ellos sacó de un pequeño bolso de piel de tigre, un papel escrito y plegado que entregó al gobernador. Se trataba de un certificado de varios gobernadores españoles que declaraban ser uno de aquellos indios de la raza de los caciques y actualmente jefe de toldería. El indio pidió que se le diera un nuevo certificado, ya que el viejo estaba roto en los pliegues por el uso. Le fue concedido. Evidentemente, estos indígenas desconocen la lengua española, de la que no pronunciaron una sola palabra. Un oficial nos ha dicho que hablan la lengua de Pará, mezclada con la de los indios de las tierras vecinas (Pernetty ápud López Mazz y Bracco 2010: 203).

Andando el tiempo, en 1812, el capitán Baltasar Vargas le escribe a su comandante Sarratea, diciéndole que el Caciquillo, un caudillo indígena de los indios de Misiones, trae un "adjunto" y probablemente otros papeles:

Con esta fecha llegué a incorporarme con mi gente donde no puedo menos que comunicarles a vuestra excelencia que encontrándome con el Caciquillo en mi campamento que ha llegado de paseo, con una escolta de ocho indios, estos vienen decentes. También traen dos chapeados muy hermosos; (...) preguntándoles como les había ido por dentro me mostró el adjunto dicho Caciquillo, el que copié para satisfacción de vuestra excelencia. Yo me presumo, él tendrá otro papel (López Mazz y Bracco 2010: 246).

También encontramos testimonios de uso de la tecnología de la escritura en otras lenguas europeas. En 1722, el Gobernador de Colonia del Sacramento se dirige al rey describiendo la relación con los guenoa-minuanes. En ese documento se puede ver el acceso a la lengua escrita en contextos de habla portuguesa, incorporado a un conjunto de bienes culturales: 
este año tengo hecho con ellos [los minuanes] grande gasto en aguardiente, tabaco, cuchillos, yerba mate, uniformes, a todos los caciques con chaquetas, calzones, camisas, sombreros, dando a todos bastones y patentes... Las cartas adjuntas son las que me escriben [los minuanes] cuando necesitan alguna cosa y no pueden venir personalmente (López Mazz y Bracco 2010: 107).

La incorporación de esta tecnología no es un elemento aislado sino que es uno más entre otros elementos de la cultura europea que los grupos indígenas integran $^{12}$. Además, por ejemplo, del intercambio de bienes materiales como se ve en la cita anterior (aguardiente, tabaco, cuchillos, uniformes, chaquetas, calzones, camisas, sombreros, bastones), también se traspasaron, en general del mundo europeo hacia el mundo indígena, prácticas culturales como el cambio de nombres indígenas por nombres europeos (Azara 1896 ápud Lezama 2008: 28 y 60). El reconocimiento y la valorización de la tecnología de la escritura se enmarca en un proceso mucho más complejo como fue el intento de incorporar a las poblaciones indígenas americanas al mundo económico, religioso y cultural de origen europeo.

\section{SÍNTESIS Y PONDERACIONES FINALES}

Identificamos aquí las circunstancias por las cuales las modalidades lingüísticas habladas en el actual territorio uruguayo al momento de la llegada de los europeos entran, a excepción del guaraní, en la categoría de lenguas extintas.

Postulamos dos etapas en la historia lingüística del contacto entre españoles e indígenas de diversas etnias. La primera de estas etapas abarca los acercamientos iniciales (siglo xVI) y la segunda, el establecimiento y colonización europeos (siglos XVII y XVIII) que culminará con la aculturación lingüística de los indígenas (siglo XIX). Los primeros contactos estuvieron mediados por intérpretes naturales, tanto europeos que aprenden lenguas indígenas como indígenas que aprenden español, que, como hemos visto,

12 Esto ha sido explícitamente señalado por Lezama: "Este aspecto de la situación dará lugar a lo que considero la "creación de una nueva tribu" conformada por los indios que se identifican con las nuevas tecnologías y con los nuevos símbolos culturales que marcan su preponderancia política, como los nombres, el idioma, la vestimenta y la religión aportados por los europeos" (Lezama 2008: 47). 
lo hacen por diferentes razones y motivaciones. Durante el establecimiento y la colonización europeos, también hay dos situaciones paralelas: hubo tanto indígenas que aprendieron español, como españoles que aprendieron lenguas indígenas. Los indígenas lo hacen en el marco de un proceso de hispanización que incluye también adoptar de la sociedad que los coloniza bienes inmateriales y materiales. Esta hispanización tiene como correlato el desplazamiento y la pérdida de las lenguas indígenas de la región y la incorporación del español. Algunos estudiosos de principios del siglo XIX son conscientes de esto e intentan compilar algunas de estas lenguas, con el afán de su registro y conservación.

Un haz de circunstancias explica la pérdida de las lenguas indígenas. Las circunstancias sociodemográficas analizadas dan cuenta de la extinción de buena parte de la población hablante de estas lenguas. Las circunstancias etnolingüísticas muestran que la incorporación de una nueva lengua (y que esta fuera eventualmente una lengua vehicular) al repertorio comunicativo de los indígenas de la zona era una práctica naturalizada y, por tanto, no ajena a la historia cultural de esos pueblos. Las circunstancias históricoculturales ponen en evidencia diferentes procedimientos por los cuales la cultura hispana, y con ella la lengua española, terminan por prevalecer en la región, aunque no debemos dejar de lado el papel del guaraní, lengua de comunicación interétnica y lengua de evangelización. Las circunstancias tecnológicas se resumen fundamentalmente en el hecho de que el español tuviera asociada la poderosa tecnología de la escritura, que pasa a formar parte de la vida cotidiana de buena parte de la población indígena como un bien deseable. La incorporación de esta tecnología no es un elemento aislado sino que es uno más entre otros elementos de la cultura europea que los grupos indígenas incorporan.

Estas circunstancias no son ajenas a lo que pasó en el resto de Hispanoamérica. Quizás la diferencia fundamental radique en que en el territorio del Río de la Plata el proceso se da más rápida y radicalmente por las características culturales de los pueblos originarios, por el tipo de relación con los pueblos indígenas y por las propias características de la colonización. La preocupación de la Corona española por estos territorios fue tardía, y cuando la hubo fue en una época en que la Corona ya no señalaba interés alguno en el mantenimiento de las lenguas indígenas, como lo muestra la Real Cédula de 1770 sobre la necesidad de extinción de las lenguas indígenas (ápud Merma Molina 2005: 177).

Este trabajo constituye un aporte al estudio histórico del contacto lingüístico que en este caso tiene como resultado el desplazamiento y pérdida de lenguas indígenas autóctonas en el Río de la Plata. Es este hecho una pieza más en el complejo mosaico de la historia lingüística del Uruguay. 


\section{REFERENCIAS BIBLIOGRÁFICAS}

Acevedo Díaz, Eduardo. 1889[1964]. Nativa. Biblioteca Artigas, Colección de Clásicos Uruguayos. Vol. 53. Montevideo: Ministerio de Instrucción Pública y Previsión Social.

Alonso Araguás, I. 2010. Figuras mediadoras y espacios fronterizos. Algunos lugares comunes. En Grupo Alfaqueque (ed.). Los límites de Babel. Ensayos sobre la comunicación entre lenguas y culturas, 47-76. Madrid/Frankfurt: Iberoamericana-Vervuert.

Azara, FÉlix DE. 1847. Descripción e historia del Paraguay y del Río de la Plata. s/d.

Barrios Pintos, Aníbal. 1971. Historia de los pueblos orientales. Montevideo: Ediciones de la Banda Oriental.

Bértola, Cecilia y Amparo Fernández. 2011. Notas para el estudio de las voces intérprete, ladino y lenguaraz en territorio oriental (siglos XVII a XIX). Ponencia presentada en el V Seminario sobre lexicología y lexicografía del español y del portugués americanos: a 200 años del inicio del proceso independentista del Uruguay, Montevideo, Uruguay.

Bértola, Cecilia. 2013. Filólogos naturalistas en la Banda Oriental en los siglos XVIII y XIX: estudio lingüístico comparativo entre el legado de un naturalista demarcador y el de un demarcador naturalista. Monografía de la asignatura Lingüística Histórica de la Licenciatura en Lingüística de la Facultad de Humanidades y Ciencias de la Educación, Universidad de la República. Disponible en http://www.historiadelaslenguasenuruguay. edu.uy/?page_id=1064. [Consulta 14/06/2013].

Bertolotti, Virginia. 2011a. El español y las lenguas indígenas en el Río de la Plata: análisis de una causa judicial de 1686. Ponencia presentada en I Simposio de la Lengua Española y IV Coloquio de Historia del Español organizado por el Departamento Nacional de Español de la Administración Nacional de la Enseñanza Pública, 1 de setiembre de 2011, Montevideo. 2011b. Los cambios en la segunda persona del singular durante el siglo XIX en el español del Uruguay. Tesis de doctorado. Universidad de Rosario, Argentina.

Bertolotti Virginia y Magdalena Coll. 2006. Apuntes sobre el español en el Uruguay: historia y rasgos caracterizadores. Ámbitos 16: 31-40.

2010. La historia lingüística del Uruguay: fuentes, resultados y perspectivas. En Cristina Píppolo y Adriana Uribarrí (coords.). Español en cambio, pp. 48-72. Montevideo: Instituto de Profesores Artigas.

Bertolotti, Virginia; Magdalena Coll y Ana Clara Polakof. 2010. Documentos para la historia del español en el Uruguay. Vol. 1. Montevideo: Facultad de Humanidades y Ciencias de la Educación.

Bracco, Diego. 2004. Charrúas, guenoas y guaranies. Interacción y destrucción: indígenas en el Río de la Plata. Montevideo: Linardi y Risso.

Bracco, Diego y José López Mazz. 2006. La insurrección de 1686. Charrúas, pampas y serranos, chanáes y guaranies. Montevideo: Linardi y Risso.

2010. Minuanos: apuntes y notas para la historia y la arqueología del territorio guenoa-minuan. Montevideo: Linardi \& Risso.

Coll, Magdalena. 2008. Estudios sobre la historia del portugués en el Uruguay: estado de la cuestión. En Jorge Espiga y Adolfo Elizaincín. Español y Portugués: um (velho) Novo Mundo de fronteiras e contatos: 23-64. Pelotas, Rio Grande do Sur: Educat (Editora da Universidade Católica de Pelotas).

2010. El habla de los esclavos africanos y sus descendientes en Montevideo en los siglos XVIII y XIX: representación y realidad. Montevideo: Ediciones de la Banda Oriental.

Consens, Mario. 2010. Extinción de los indígenas en el Río de la Plata. Montevideo: Linardi y Risso. 
1997. Prehistoria del Uruguay. Montevideo: CIARU.

Curbelo, Carmen y Roberto Bracco. 2004. La construcción del espacio misionero y la toponimia en territorio uruguayo. En María Teresa Carrara (comp.). Cambio Cultural en Arqueología Histórica, Actas del Tercer Congreso Nacional de Arqueología Histórica: 407-413. Rosario: Escuela de Antropología, Facultad de Humanidades y Artes, Universidad Nacional de Rosario.

Da Rosa, Juan Justino (en proceso). Historiografía lingüística del Río de la Plata: las lenguas indígenas.

Farías, María y Antonio Lezama (en prensa). La cuestión guaraní como un problema de perspectiva.

Fernández Guerra, Amparo y Cecilia Bértola. 2011. Notas para el estudio de las voces intérprete, ladino y lenguaraz en territorio oriental (siglos XVII a XIX). Ponencia presentada en el $V$ Seminario sobre lexicología y lexicografia del español y del portugués americanos: a 200 años del proceso independentista del Uruguay. Montevideo, 13 de octubre de 2011. Disponible en http://www.mec.gub.uy/academiadeletras/MarcoPrincipal.htm. [Consulta 17/06/2013].

Gómez Haedo, JuAn Carlos. 1937. Un vocabulario charrúa desconocido. Boletín de Filología 1/4-5: 323-49. Montevideo, Instituto de Estudios Superiores.

Hervás y Panduro, Lorenzo. 1787. Catecismo de guenoa. En el Saggio prattico delle lingue. Cesena, pp. 228-229.

Lamas, Andrés y Pablo Blanco Acevedo. 1922. Escritos selectos del Dr. D. Andrés Lamas. Montevideo: Tipografia de Arduino Hnos.

Larrañaga, Dámaso Antonio. 1923. Compendio del idioma de la Nación Chaná. En Escritos de D. Dámaso A. Larrañaga, tomo III: 163-174. Montevideo: Instituto Histórico y Geográfico del Uruguay, Imprenta Nacional.

1951 [1816]. Descripción de las fiestas cívicas celebradas en Montevideo. Colección de Impresos Raros Americanos. Montevideo: Universidad de la República/ Facultad de Humanidades y Ciencias.

LEVINTON, NORBERTO. s/d. Guaraníes y charrúas:una frontera exclusivista-inclusivista. Revista Contratiempo. Disponible en http://www.revistacontratiempo.com.ar/levinton_charruas_ fronteras.htm. [Consulta 17/06/2013].

Lezama, Antonio. 2008. La historia que nos parió. Montevideo: Linardi y Risso.

López Mazz, José y Diego Bracco. 2010. Minuanos. Apuntes y notas para la historia y la arqueología del territorio guenoa-minuán (Indígenas de Uruguay, Argentina y Brasil). Montevideo: Linardi y Risso.

Martinell Gifre, Emma. 1992. El papel de los intérpretes. En Emma Martinell Gifre (ed.). La comunicación entre españoles e indios: palabras y gestos: 151-205. Madrid: Editorial Mapfre.

Medina, José Toribio. 1908. Los viajes de Diego García de Moguer al Río de la Plata. Estudio Histórico. Santiago de Chile: Imprente Elzeviriana.

Merma Molina, Gladys. 2005. Antecedentes históricos del contacto entre el español y las lenguas indígenas americanas: los intérpretes indígenas, la iglesia y los españoles que se incorporaron a la vida indígena. Res Diachronicae Virtual 4: El Contacto de Lenguas. Número monográfico coordinado por Ana Rodríguez Barreiro y Ana García Lenza. 171-183.

Pi Hugarte, Renzo. 2005. Historias de aquella "gente gandul". Montevideo: Ediciones Debolsillo.

Rona, José Pedro. 1964. Nuevos elementos acerca de la lengua charrúa. Facultad de Humanidades y Ciencias. Departamento de Lingüística, Montevideo.

VIDART, DANIEL. 2000. La trama de la identidad nacional. Tomo III. Montevideo: Ediciones de la Banda Oriental. 